\title{
Sequential correction of caustic stricture of trachea and esophageal orifice
}

\author{
Ming-Ho Wu* and Han-Yun Wu \\ Department of Surgery, Tainan Municipal Hospital 670 Chung-Te Rd, Tainan, Taiwan
}

\begin{abstract}
We describe a case of late caustic stricture of trachea and esophageal orifice sequentially treated by tracheoplasty and slide pharyngo-esophagoplasty. The tracheoplasty consisted of tracheal segmental resection, middle split of thyroid-cricoid cartilage, and following telescope anastomosis. A slide pharyngo-esophagoplasty was limited at the neck. The patient was uneventful after the sequential surgical correction.
\end{abstract}

\section{Introduction}

In our previous report, of 370 patients with acid corrosive injury around $4 \%$ patients had acid aspiration injury [1]. Meanwhile, of 50 patients with high-level esophageal stricture around $10 \%$ had laryngotracheal stricture [2]. In most cases of caustic esophageal stricture associated with airway stricture, the surgical result of esophageal reconstruction is not favorable. Here, we will describe a case of late caustic stricture of trachea and esophageal orifice successfully treated by tracheoplasty and sequential slide pharyngo-esophagoplasty.

\section{Case presentation}

A 48-year-old female patient suffered from corrosive injury at the age of 23 , with resultant respiratory and swallowing problems. She initially underwent hemigastrectomy and airway management at a medical center, followed by tracheal T-tube insertion at a second medical center in the same year, and tracheal segmental resection at a third medical center in the following year. Unfortunately, she experienced intermittent dyspnea after surgery. At the age of 44 , she visited our outpatient clinic because of progressive dyspnea. Bronchoscopy and computerized tomography revealed the airway stricture involving the subglottis and proximal trachea (Figure 1A). She underwent a tracheoplasty which consisted of segmental resection of four tracheal rings, middle split of thyroid-cricoid cartilage, and following telescope anastomosis (Figure 1B). The endotracheal tube was removed on postoperative day 2 and she was discharged uneventfully on post-operative day 7. She was doing well in a 4 years follow-up (Figure 1C). Meanwhile, she only tolerated liquid diet since the year of corrosive injury. Caustic stricture of the esophageal orifice was confirmed by esophagography (Figure 2A), that was resistant to balloon dilation. She underwent a slide pharyngo-esophagoplasty (Figure $2 \mathrm{~B}-2 \mathrm{C}$ ) at the age of 47 . She could swallow regular diet in one year follow-up.

\section{Comments}

Corrosive injury can cause solitary esophageal stricture or multiple esophageal strictures. A few patients with ingestion of corrosive agent had combined stricture of the esophagus and the airway. In case of the combined stricture, surgeons usually face a challenging reconstructive problem. [2]. In pursuit of literature, subglottic stenosis could be treated using different surgical procedures [3-7]. In the management of subglottic stenosis, we perform middle split of thyroid-cricoid cartilage following telescope anastomosis. The non-graft surgical procedure has no issue of graft necrosis or graft displacement. In comparing to cricotracheal resection, this procedure can preserve the cricoid cartilage and surrounding tissue to ensure a firm and secure laryngo-tracheal anastomosis, and less injury to the recurrent laryngeal nerves. At surgery, careful middle split of the thyroid-cricoid cartilage, the vocal cords, whole airway lumen, and esophagus could be well visualized that ensures security of the vocal cords and esophagus. Stent placement or T-tube insertion is not necessary in the procedure. For anastomotic security, heavy absorbable sutures, such as $2-0$ or $1-0$, is recommended.

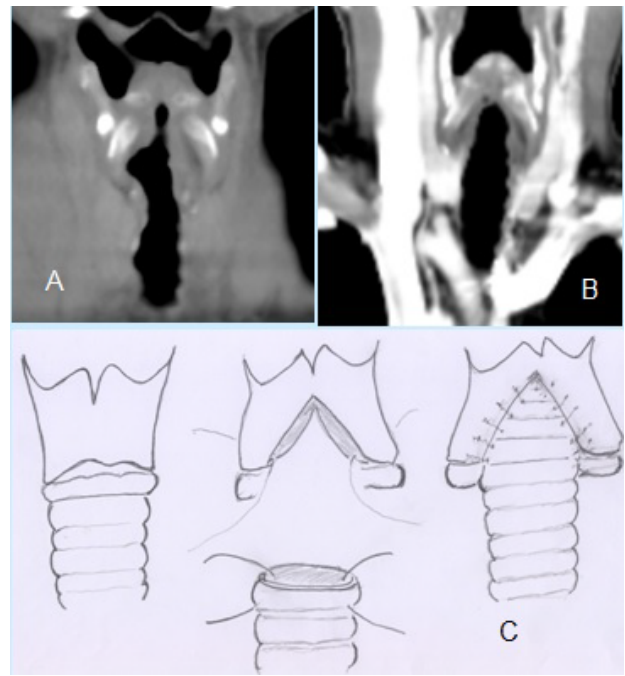

Figure 1. Airway stricture involves the subglottis and proximal trachea (A). The airway is patent (B) after tracheoplasty (C).

Correspondence to: $\mathrm{Dr}$. Ming-Ho Wu, 670 Chung-Te Rd, Tainan, Taiwan, 701 ROC, Tel 886-6-2609926; Fax: 886-6-2606351; E-mail: m2201@mail.ncku.edu.tw

Key words: caustic stricture, tracheoplasty, slide pharyngo-esophagoplasty

Received: June 27, 2016; Accepted: July 19, 2016; Published: July 22, 2016 


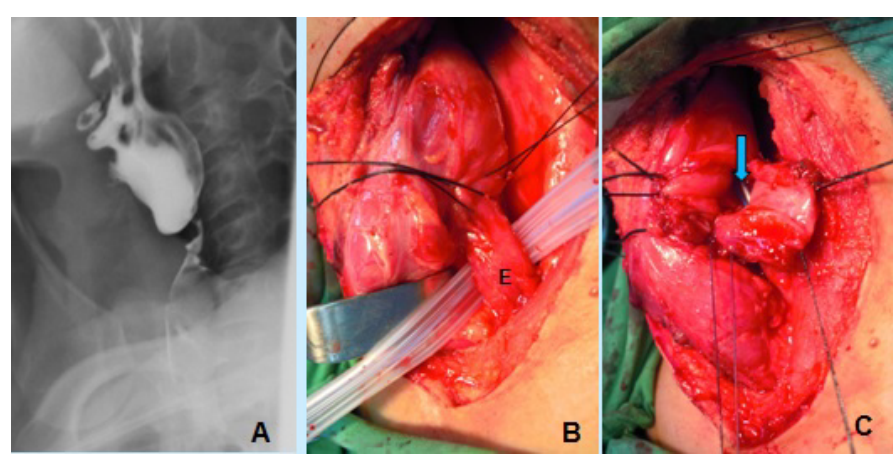

Figure 2. Esophagography shows stricture of esophageal orifice (A). The cervical esophagus (E) was mobilized (B). At slide pharyngo-esophagoplasty, a nasogastric tube (arrow) is inserted while completion of right-half anastomotic sutures (C).

The innovative technique of middle split and telescope anastomosis is a good alternative procedure for the treatment of subglottic stenosis. Esophageal reconstruction using ileocolon is commonly performed for multiple esophageal strictures [2]. However, a localized stricture of cervical esophagus could be treated by cervical approach only, the use of esophageal conduit is not necessary. Slide pharyngo-esophagoplasty is optimal method in the treatment of solitary stricture of esophageal orifice.

\section{References}

1. Tseng YL, Wu MH, Lin MY, Lai WW (2002) Outcome of acid ingestion related aspiration pneumonia. Eur J Cardiothorac Surg 21: 638-643. [Crossref]

2. Wu MH1, Tseng YT, Lin MY, Lai WW (2001) Esophageal reconstruction for hypopharyngoesophageal strictures after corrosive injury. Eur J Cardiothorac Surg 19: 400-405. [Crossref]

3. Richardson MA, Inglis AF Jr (1991) A comparison of anterior cricoid split with and without costal cartilage graft for acquired subglottic stenosis. Int $J$ Pediatr Otorhinolaryngol 22: 187-93. [Crossref]

4. Zalzal GH (1993) Treatment of laryngotracheal stenosis with anterior and posterior cartilage grafts. A report of 41 children. Arch Otolaryngol Head Neck Surg 119: 82-86. [Crossref]

5. Cotton RT, Mortelliti AJ, Myer CM 3rd (1992) Four-quadrant cricoid cartilage division in laryngotracheal reconstruction. Arch Otolaryngol Head Neck Surg 118: 1023-1027. [Crossref]

6. Gerber ME, Modi VK, Ward RF, Gower VM, Thomsen J (2013) Endoscopic posterior cricoid split and costal cartilage graft placement in children. Otolaryngol Head Neck Surg 148: 494-502. [Crossref]

7. Boseley ME, Hartnick CJ (2006) Pediatric partial cricotracheal resection: a new technique for the posterior cricoid anastomosis. Otolaryngol Head Neck Surg 135: 318 322. [Crossref]

Copyright: (C2016 Wu MH. This is an open-access article distributed under the terms of the Creative Commons Attribution License, which permits unrestricted use, distribution, and reproduction in any medium, provided the original author and source are credited. 